\title{
Beam steering in a Half-Frequency driven Airborne CMUT transmitter array
}

\author{
Talha Masood Khan \\ UNAM-National Nanotechnology Research \\ Center, Institute of Material Science and \\ Nanotechnology, Bilkent University \\ Ankara, Turkey \\ talha.khan@bilkent.edu.tr
}

\author{
A. Sinan Tasdelen \\ Bilkent University Acoustics and Underwater \\ Technologies Research Center, Bilkent \\ University \\ Ankara, Turkey \\ sinan@ee.bilkent.edu.tr
}

\author{
Mehmet Yilmaz \\ UNAM-National Nanotechnology Research \\ Center, Institute of Material Science and \\ Nanotechnology, Bilkent University \\ Ankara, Turkey \\ mehmetyilmaz@unam.bilkent.edu.tr
}

\author{
Abdullah Atalar \\ UNAM-National Nanotechnology Research \\ Center, Bilkent University Acoustics and \\ Underwater Technologies Research Center \& \\ Electrical and Electronics Engineering \\ Department, Bilkent University, \\ Ankara, Turkey \\ aatalar@bilkent.edu.tr
}

\author{
Hayrettin Koymen \\ UNAM-National Nanotechnology Research \\ Center, Bilkent University Acoustics and \\ Underwater Technologies Research Center \& \\ Electrical and Electronics Engineering \\ Department, Bilkent University, \\ Ankara, Turkey \\ koymen@ee.bilkent.edu.tr
}

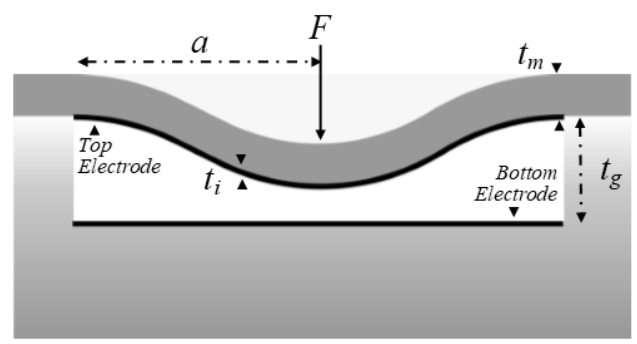

Fig. 1. Cross section of a single CMUT element. The flexed membrane is made of $40 \mu \mathrm{m} \mathrm{Si}$, and $100 \mathrm{~nm}$ of $\mathrm{Al}_{2} \mathrm{O}_{3}$

\section{Designing AND Modelling}

In principle CMUT operates at a fixed DC bias generating a strong deflecting force on the membrane. Earlier works [5] show that operating a CMUT in an unbiased mode (half frequency) enables a full swing in the gap without collapsing. Using an accurate equivalent circuit model based characterization, a performance analysis is achieved. [3].

The capacitance, $\delta C(r ; t)$, of a concentric narrow ring on the plate of radius $r$ and width $d r$ can be expressed as

$$
\delta C(r ; t)=\frac{\varepsilon_{o} 2 \pi r d r}{t_{g e^{-x}(r, t)}}=\frac{\varepsilon_{o} 2 \pi r d r}{t_{g e^{-x_{p}}(t)\left(1-\frac{r^{2}}{a^{2}}\right)^{2}}}
$$

Where $\varepsilon_{0}$ is permittivity of the gap, and $t_{g e}$ is the effective gap $\left(t_{g}+t_{i} / \varepsilon_{r}\right)$.

For transmitting CMUT elements, Large Signal Equivalent model was used (Figure 2). $C_{R m}$ and $L_{R m}$ are the compliance of the plate and the inductance corresponding to the mass of the plate suitable for the $\left\{\mathrm{f}_{\mathrm{R}}, \mathrm{v}_{\mathrm{R}}\right\}$ rms model. $Z_{R R}$ is the radiation resistance of the element. The left hand side of the figure shows the electrical end of the circuit model, while left hand side the mechanical side. wave is produced by application of electrical signal between top and bottom electrodes of CMUT [4]. 
Device parameters of $t_{m}=40 u m, t_{i}=100 \mathrm{~nm}, \varepsilon_{r}=9.5$ (Alumina), were used to derive radius $a$ using the following equation. [6]

$$
f_{r}=\frac{t_{m}}{a^{2}} \frac{1}{2 \pi} \sqrt{\frac{80 Y_{0}}{9 \rho_{m}\left(1-\sigma^{2}\right)}}=3805 \frac{t_{m}}{a^{2}}
$$

For a $f_{r}=77 \mathrm{kHz}, t_{m} / a_{2}$ is 20.24 , which in turns makes $a=1.4 \mathrm{~mm}$. Hence to limit peak deflection of large $k a$ of 2 , $t_{g} / t_{m}=0.25$ was used ( $k$ is wave number). A $t_{g}$ of $10 u m$ was extracted through simulation for this purpose (This enables the plate to operate in linear elastic regime). For these parameters, $F_{b} / F_{g}=0.673$ was derived, which was enough to produce $6 \mu \mathrm{m}$ of peak deflection. For an un-collapsed airborne CMUT transmitter simulation, the material parameter in table 1 were used. For an array, spacing $d$ of $3 \mathrm{~mm}$ was selected to comply with material geometry (Figure 3). An Advanced Design System (ADS) simulation of this cell produced a Q factor of 206 (Figure 4).

\section{FABRICATION}

After the design process, a photomask containing various arrays and array types was designed. The fabrication of CMUT arrays was divided into two parts, $420 \mu \mathrm{m}$ thick SOI and $500 \mu \mathrm{m}$ thick Pyrex wafer. The SOI wafer was first cleaned using a RCA method followed by Piranha cleaning. 100nm of Aluminum oxide $\left(\mathrm{Al}_{2} \mathrm{O}_{3}\right)$ was deposited on device side of SOI wafer using a thermal Atomic Layer Deposition (ALD) process.

The Pyrex wafer was processed by initiating with a single photolithographic process followed by wet etching $10 \mathrm{um}$ trenches into Pyrex wafer and further coated with a Metal stack $(100 \mathrm{~nm} \mathrm{Ti} / 100 \mathrm{~nm} \mathrm{Pt} / 50 \mathrm{~nm} \mathrm{Au}$ ) (Figure 5). Once both of the wafers were processed, they were anodically bonded (Figure 6). Following this, the Handle layer was plasma etched using a specialized, isotropic, Reactive Ion Etch (RIE) process in an Inductively Coupled Plasma (ICP) chamber. Removal of the handle layer revealed the buried oxide layer over the Device layer, which was carefully removed using a wet Buffer Oxide Etch (BOE) etchant.

The devices were sealed using a sealing epoxy and the cavities underneath them were vacuumed. A PCB was designed to take out connections from the wafer to be soldered onto the electronics.

\section{CharecterizATION AND TESTING}

\section{A. Impedance Measurements}

An impedance analyzer (HP 4194A) was used to measure the impedance characteristics of the CMUT arrays. The measurements were carried out in two modes, which are, array mode (all elements connected as shown in Figure 7) and element mode (single element biased while the others are grounded). For a CMUT array, measured and simulated results were correlated. A modified large circuit equivalent model was used to include the losses into the simulations. Figure 8 shows a fitted and measured conductance characteristic of a $3 \times 3$ array. The resonant frequency was shifted to $75 \mathrm{kHz}$ owing to change in material parameters.
TABLE I. MATERIAL PARAMTERS FOR SIMULATION

\begin{tabular}{lcc}
\hline Parameters & Si & Air \\
\hline Young's Modulus & $148 \mathrm{GPa}$ & \\
\hline Poisons Ratio & 0.17 & \\
\hline Density $\left(\mathrm{kg} / \mathrm{m}^{3}\right)$ & 2370 & 1.27 \\
\hline Speed of Sound $(\mathrm{m} / \mathrm{s})$ & & 331
\end{tabular}

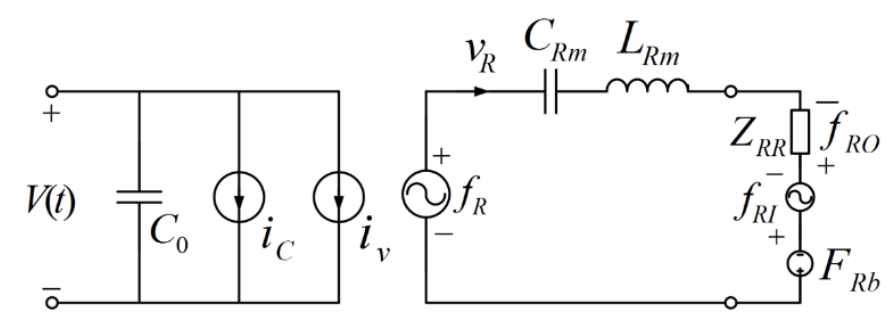

Fig. 2. Large signal Equivalent model for designing a CMUT transmitter. Left hand side depicts the electrical while the right hand side shows mechanical side.

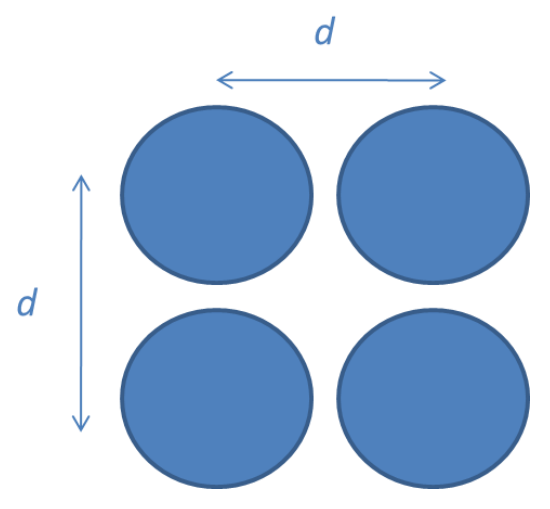

Fig. 3. A $2 \times 2$ array with a pitch $(d)$ of $3 \mathrm{~mm}$

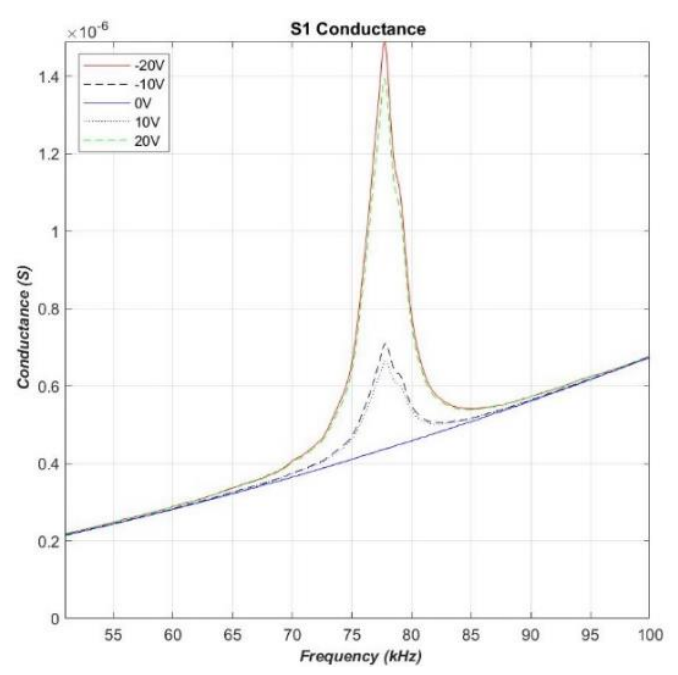

Fig. 4. Conducatance performance of a $2 \times 2$ array under bias of $-20 \mathrm{~V}$ to $+20 \mathrm{~V}$ 


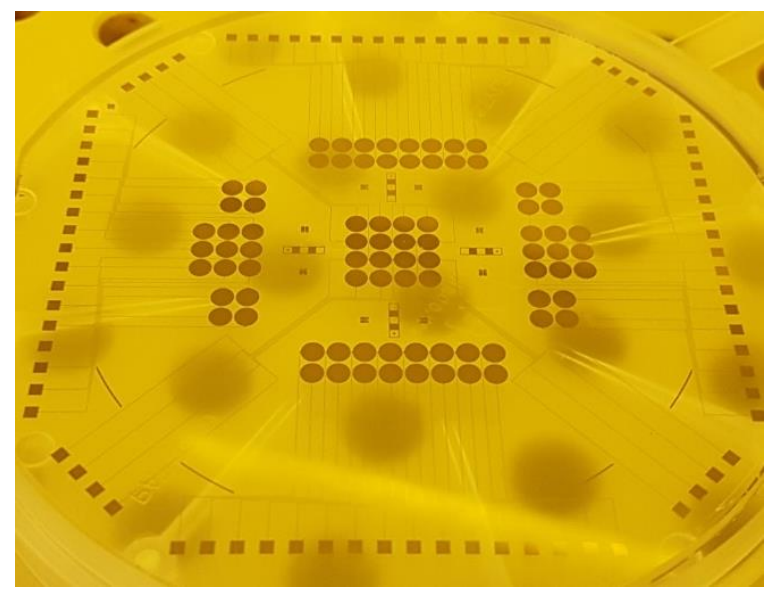

Fig. 5. An unbonded pyrex wafer with CMUT arrays on top

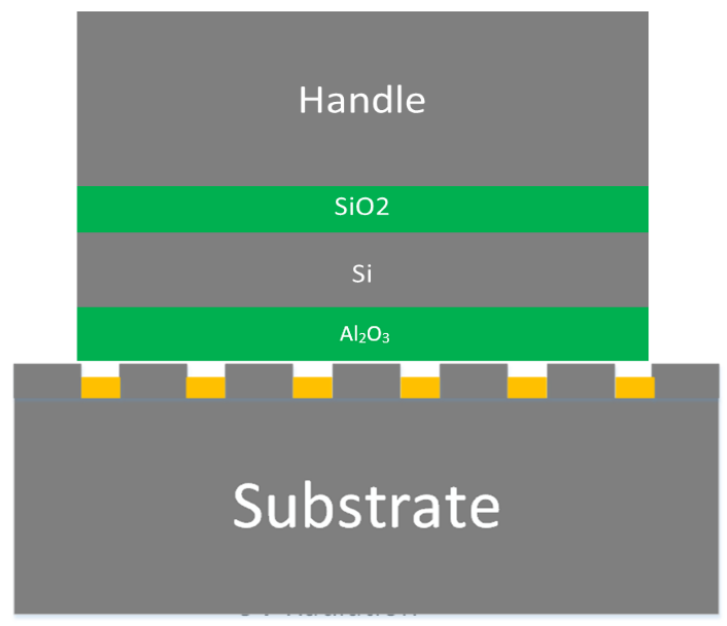

Fig. 6. Crossection of Bonded Pyrex (bottom) and SOI wafer (Top)

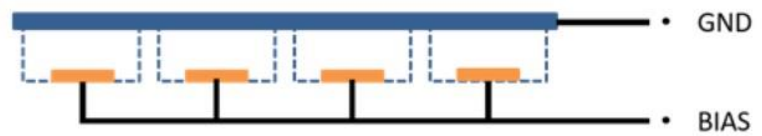

Fig. 7. Measurement configuration for Impedacne charecterization of a $2 \times 2$ array.

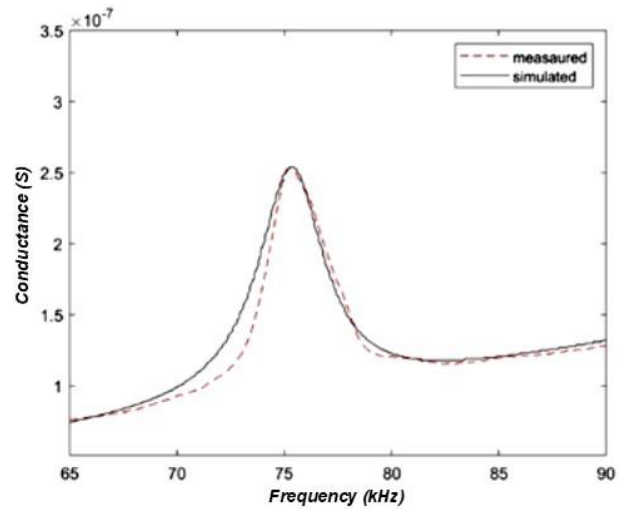

Fig. 8. Measured and fitted conductance values for a $3 \times 3$ CMUT array

\section{B. Pressure Measurements}

An NI-DAQ card PXI 6733 was used to drive a 2x2 array at no bias (Half Frequency). A setup was devised to measure the radiated pressure using a BK-4138 microphone at varying height and angles (Figure 9). An A.C. signal of $10 \mathrm{~V}_{\mathrm{p}-\mathrm{p}}$ was used to excite the element at $38 \mathrm{kHz}$. Microphone placed at $15 \mathrm{~mm}$ height has a preamplifier that converts acoustic pressure into amplitude change. This received in real time on a Lab-View interface (Figure 10).

After fabrication cycle, variations in physical characteristics, such as membrane thickness or slight variation in diameter of CMUT was observed. These variations, if not accounted for properly, may result in unwanted effects, such as variations in resonant frequency, and phase difference between each element of an array. The design frequency $77 \mathrm{kHz}$ was shifted to $75 \mathrm{kHz}$ after fabrication (Figure 8). As the elements of array were wet and dry etched, there was a slight variation in the membrane thickness and vacuum inside the cavities. This resulted in a difference in pressure radiated by CMUT elements. To compensate, each element was driven separately at $10 \mathrm{~V}_{\mathrm{p}-\mathrm{p}}$ and a resulting pressure was noted. The input voltage for element producing high pressures (up to $200 \mathrm{mPa}$ ) were reduced to $7 \mathrm{~V}_{\mathrm{p}-\mathrm{p}}$ to equalize the sound pressure emitted by each element (Bringing it down to $150 \mathrm{mPa}$ ). For phase difference compensation in each element, a lock-in Amplifier (SR830) with a set time constant of $100 \mu \mathrm{s}$ and a filter roll off of $12 \mathrm{~dB} /$ octave was used. Each element in an array were driven using a single source and output signal from the microphone was connected as a reference to the lock-in Amplifier. The difference in phase detected was later added to each individual input to compensate for the inherent phase difference in each element. A phase compensation of $0.27 \pi, 0.46 \pi, 0.5 \pi$ and $0.7 \pi$ to each individual element of a $2 \times 2$ CMUT array resulted in the beam to be formed as shown in Figure 11 and Figure 12.

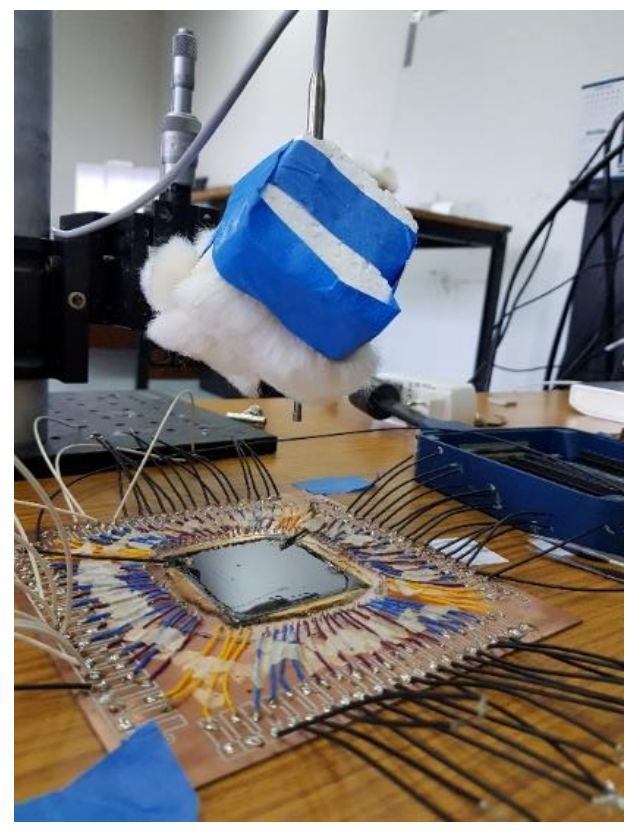

Fig. 9. The acoustic signal acquiring setup. The microphone hangs on an XYZ table that measures the pressure on varying angles. 


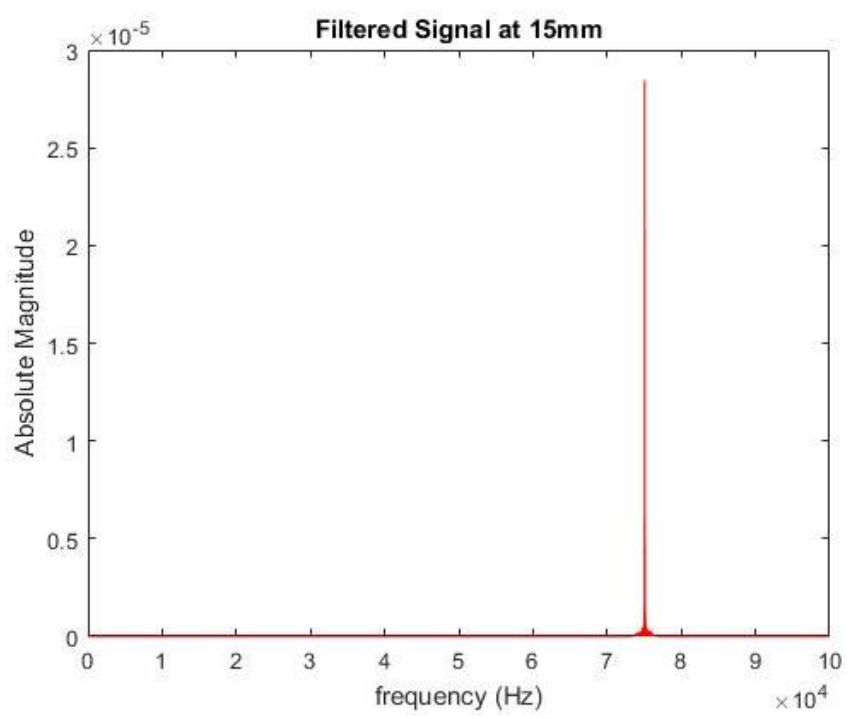

Fig. 10. An FFT (Fast Fourier Transform) of a time domain amplitude signal received from exciting a single CMUT element onto a microphone $15 \mathrm{~mm}$ away.

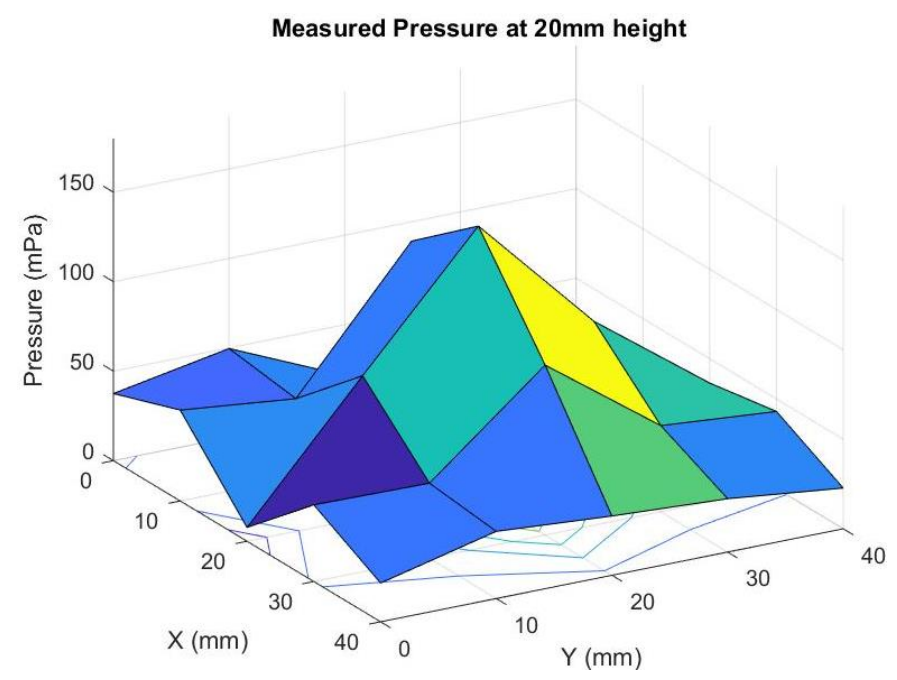

Fig. 11. Received pressure of a $2 \times 2$ array at $20 \mathrm{~mm}$ height from the array

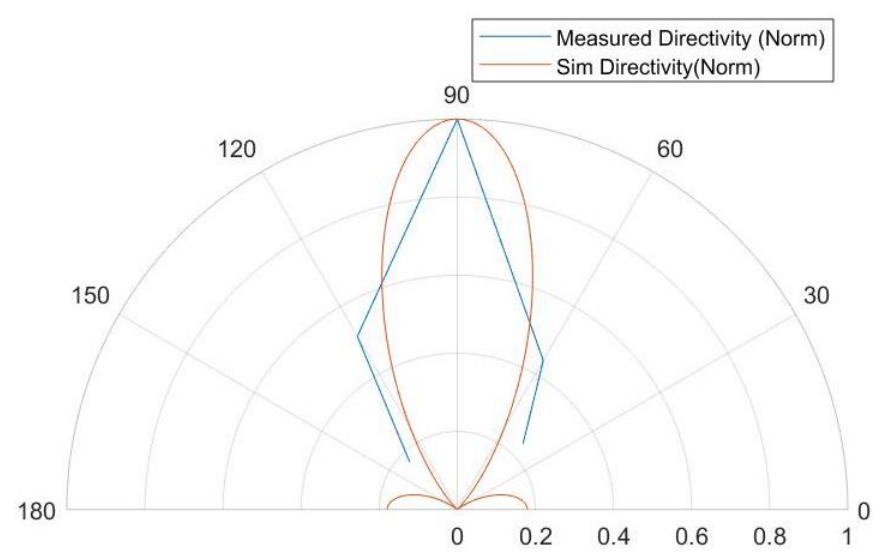

Fig. 12. Normallized acoustic pressures measured and simulted at varying angles over the CMUT array.

\section{CONCLUSION}

Airborne CMUTs have a narrow bandwidth. The minor differences in the resonance frequencies of the cells in the array must be compensated for beam forming. The measured bandwidth of $3.375 \mathrm{kHz}$ was higher than expected BW owing to various factors, including the loss of energy propagating to the surface and substrate. A pressure of $150 \mathrm{mPa}$ was measured when the array elements were driven in parallel with $10 \mathrm{~V}$ peakto-peak voltage, $20 \mathrm{~mm}$ away from the source. The arrays can be used to steer beam onto a specific angle if the appropriate compensation is added.

\section{REFERENCES}

[1] A Unlugedik, A. Atalar, and H. Koymen, "Designing an effecient wide bandwidth single cell CMUT for airbore applications using nonlinear effects," in Proc. 1EEE Ultrasonics Symp., 2013, pp.1416-1419.

[2] S. Olcum et al, "Wafer bonded capacitive micromachined underwater transducers", in Proc. lEEE Ultrasonics Symp., 2009, pp.976-977.

[3] H. Koymen, et a!., "An improved lumped element nonlinear circuit model for a circular CMUT cell," IEEE Trans. on Ultrason., Ferroelec. and Freq. Cont., vol. 59, no. 8, pp. 1791-1799, August 2012

[4] A. Unlugedik, et al., " Designing Efficient CMUT Cells for Airborne Applications," in Proc. 1EEE Ultrasonics Symp., 2014, pp.2564-2567.

[5] A. Unlugedik, et al., "Designing transmitting CMUT cells for airbore applications," IEE Trans. on Ultrason., Ferroelec. and Freq. Cont., vol 61 , Issue: 11, pp. 1899-1910, November 2014,

[6] S. Timoshenko, S. Woinowsky-Krieger, and S. Woinowsky, 'Theory of plates and shells', vol. 2. McGraw-hill New York, 1959. 